\title{
SIOUAN LINGUISTICS: AN ASSESSMENT OF WHERE WE ARE
}

David S. Rood

University of Colorado

On August 6, 7, and 8, 1976, a conference was held at the State University of New York at Oswego (which was then hosting the 1976 Linguistic Institute) entitled "American Indian Linguistics: An Assessment." Representative reports were solicited for each of the North and Central American language families. I was Invited to share with Wallace Chafe the report on Caddoan and Siouan, and my part in that division of labor turned out to be Siouan.

My perception of my assignment was that there should be an assessment of all work done and in progress on Siouan languages, with an eye to pointing out areas of need for future work. As it turned out, I interpreted the job too broadly, for the irtention of the conference was to focus specifically on historical and comparative work with the families. Consequently, I have had to prepare two papers: one general one, and one specifically historical. The historical one will be published with the proceedings of the conference, probably some time in 197?. But because the general one has seemed to draw together in one place a great deal of information otherwise unavailable, several people encouraged me to seek publication for it elsewhere, so here it is. The 
information contained herein was current in september of 1976; probably by the time you read this, some "in propress" materials will have been completed, and a number of institutional affiliations will have changed. It would be very helpful if those who detect errors or omissions in this description would let me know about them. Perhaps some sort of "current state of the art" report can be issued relatively regularly from now on. When the existence of the conference was firmly established in May, I immediately wrote to every practicinf Siouanist I kn:N about, including graduate students, and asked for help in compling, up-to-date information. Most of the letters were answered promptly and in detail; consequently, many different people are responsible for the information gathered here, and I hope I have acknowledged each one appropriately. Although in general only last names are cited below, I will be very happy to provide further identification for anyone who writes to ask.

My discussion is really an exposition of the various tables, each of which summarizes a kind of Iinguistic work on the family. The Slouan languages are listed according to the most generally accepted classification, that of voegelin (194.b). T have omitted Catawba-like Woccon, which is known only from a 1709 word list (see Chafe 1973). The two question marks have to do with Winnebago - whether it is a dialect of Chiwers or a closely related language - and Mandan - whether 1t is pnrt of the Mississippi Valley subgroup or itself a separate group. Kenneth Miner, who is probably in the best position to know, believes that 
Winnebago-Chiwere is a coherent subgroup of Siouen, with Chiwere composed of Missouri on the one hand, and Iowa-Oto on the other. Voegelin classed Mandan with Dakota, Chiwere, and Dhegiha, but Wolff (1950), Matthews (1958, 1959b, 1970), and Chafe (1973) have all expressed the belief that it should form a subproup by itself. Note that the Dakota dialects are usually referred to by their diagnostic sound correspondences as Dakota (Santee, Yankton?), Nakota (Assiniboine, Stoney, Yankton?), and Lakote (Teton). Because the $\underline{k}$ in these names is aspirated and the $t$ is not, I prefer the spelling Dakhota (Nakhota, Lakhota), but I will bow to tradition and omit the $h$ in what follows.

\section{Table I}

Present Viability of the Languages

(Names are of sources of information, by personal communication unless otherwise noted.)

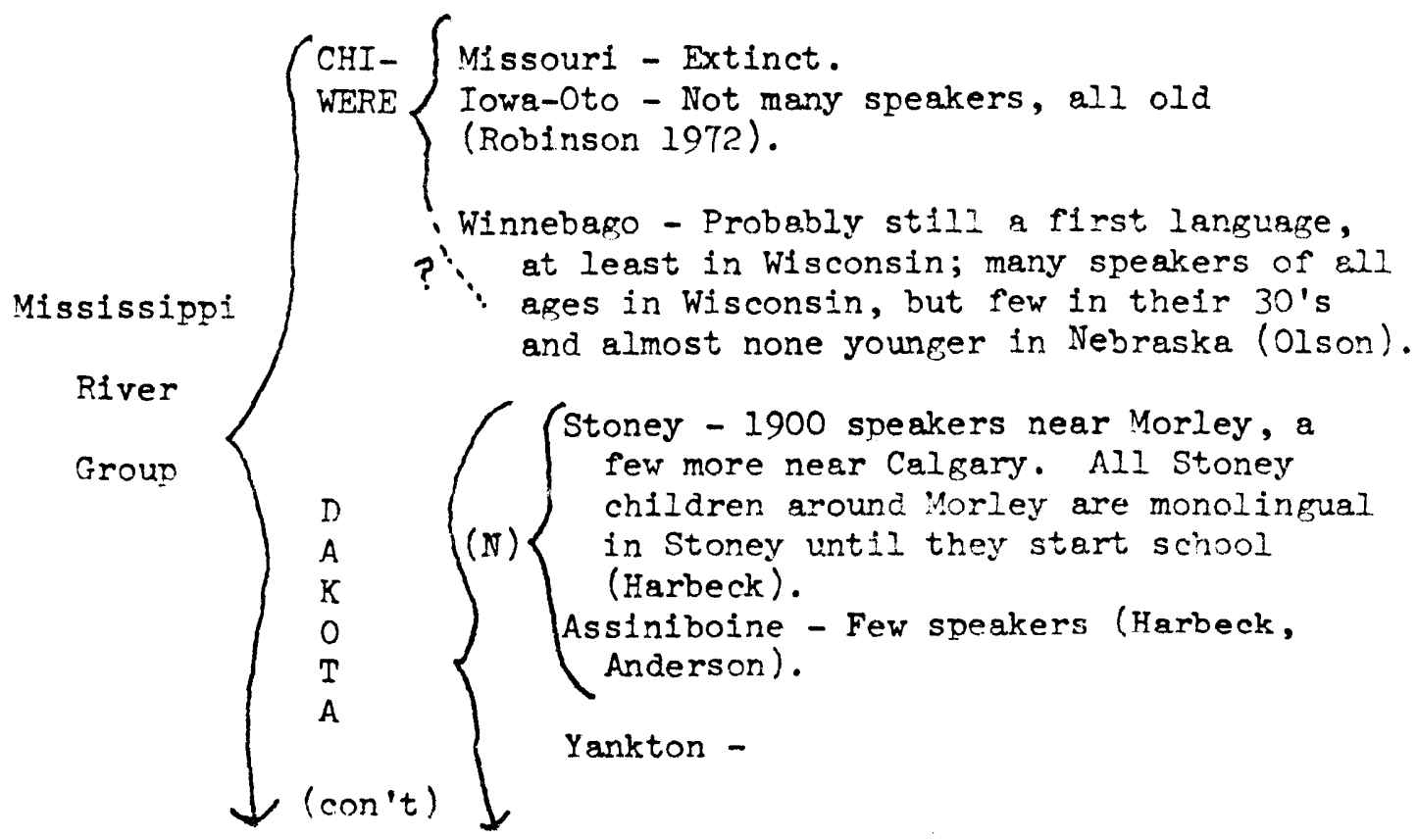






Table One spells out the current viabillty of the languages. several of which are still quite lively indeed, as North American languages go. In particular, Winnebago, Stonsy, Teton Dakota, 
Crow and possibly Hidatsa are in no danger of dying out with this or the next generation, which maans that work on those lanruages can continue for some time to come.

\section{Table 2}

Data and Analyses

\section{Dictionaries}

Iowa-oto Robinson, mimeo 1972

Winnebago Marino 1968

Stoney

Assiniboine

Santee

Riggs 1890 etc. (D-E); Williamson 1902 $(E-D)$

Teton

Buechel 1970;
Paul War Cloud
Grant 1962 ;
numerous locally
distributed
short and gener-
ally poorly
transcribed word
lists.

Kansa

Guapaw

Omaha-Pones
Phonological and Grammatical Studies

Whitman 1947;

Voegelin 1947

Susman 1941, 1943; Lipkind 1945; Marten 1964

Bellam 1975

Levin 1964;

Hollow $1970 \mathrm{~b}$

Riggs 1852, 1872, 1893; Chambers unpublished papers; Stark 1962; Drummond (in progress); Shaw (in progress); Dunnigar and Truitner 1975; Steyaert 1976

Buechel 1939; Boas and Deloria 1941; Goshe 1964; Smeall $1.972 \mathrm{a}, 1972 \mathrm{~b}$; Rood 1973; Carter 1974; Corduan 1974; Taylor 1974, 1975, 1975;

Scott 1976

Rankin $19 T^{4}$

Rankin 1974

Boas 1907; Holmer 2.945
Texts

Dorsey 1980-81

Radin 1923, 1949, 1950; Sebeok 1947

Lowie 1909, 1960c

Riggs and WIILiamson (Bible and religious literature); UND-SII workine papers; Ripgs 1893

Deloria I929, 1932,1954 , UNDSIL working papers; Powers (in progress) 


\begin{tabular}{|c|c|c|c|}
\hline Csage & LaFlesche 1932 & Wolff 1952 & Dorsey 1888 \\
\hline Mandan & $\begin{array}{l}\text { Will and Spinden } \\
1906 \text {; Hollow } \\
1970 \text { a }\end{array}$ & $\begin{array}{l}\text { Will and Sninden } \\
1306 \text {; Kennard } 1936\end{array}$ & $\begin{array}{l}\text { CHolding Eagle] } \\
\text { Lo05 [Howlow3; } \\
\text { Kennard } 1936\end{array}$ \\
\hline Crow & Lowle $1960 \mathrm{~b}$ & $\begin{array}{l}\text { Lowie 1941; Kaschube } \\
1967 \text {; Kaschube-Kamp- } \\
\text { Matthews-Gordon } \\
\text { debate in IuAt 1954- } \\
1958-1959 \text { a-1972 }\end{array}$ & $\begin{array}{l}\text { Lowle } 1930, \\
1941,19608\end{array}$ \\
\hline Hidatsa & Matthews 1873 & $\begin{array}{l}\text { Washington Matthews } \\
1874 \text {; Voegel in and } \\
\text { Harris in Lowie 1939; } \\
\text { Stetson 1946; } \\
\text { Robinett 1955; } \\
\text { Matthews } 1965\end{array}$ & Lowle 1939 \\
\hline Biloxi & $\begin{array}{l}\text { Dorsey and } \\
\text { Swanton } 1912\end{array}$ & $\begin{array}{l}\text { Dorsey 1894; Dorsey } \\
\text { and Swanton 1912; } \\
\text { Haas 1968, 1969; } \\
\text { Einaudi 1974 }\end{array}$ & $\begin{array}{l}\text { Dorsey and } \\
\text { Swanton } 1912\end{array}$ \\
\hline ofo & $\begin{array}{l}\text { Dorsey and } \\
\text { Swanton } 1912\end{array}$ & Haas 1969 & \\
\hline Tutelo & & Hale $1883 c$ & \\
\hline Cat awba & & $\begin{array}{l}\text { Gatschet } 1900 ; \\
\text { Siebert } 1945 ; \\
\text { Matthews and Red } \\
\text { Thunder Cloud } 1967\end{array}$ & $\begin{array}{l}\text { Speck } 1913,1934, \\
1946 ; \text { Matthews } \\
\text { and 8ed Thunder } \\
\text { Cloud } 1967 \text {; Cham- } \\
\text { berlain } 1888\end{array}$ \\
\hline
\end{tabular}

Table Two begins the presentation of information about work done on the individual languages by listing published materials on each language. This list duplicates and updates the information in Chafe's article in Current Trends 10 (Chafe 1973), thomph that article also includes more of the history of scholarship on these languages, while I have tried to concentrate on pomal studies rather than word lists and casual remarks. (The bibliokraphy at 
the end of this paper purposely omits all entries in the extensive bibliography appended to Chafe's article, though the reference numbers remain the same.) Additional information in Table two comes from letters and an informal bibliography complied by Michael Robert Scott, who recently completed his M.A. at the University of North Dakota.

It makes very little sense to go though a list such as this item by item. Instead, let me try to summarize for you what I think are the holes and gaps revealed by this table, and express some consequent opinions about priorities.

It is my personal opinion that it is impossible to have too many texts in any language, so that modern text collection (and publication) needs to be encouraged. Here two kinds of work are possible: new elicitation and recording, and the editing and publishing of archival materials from the American Philosophical Socfety Library and the National Archeological Archives, formerly known as the Bureau of American Ethnography, to mention only two repositories. Now that we have the University of Chicago Press Native American Texts Series, it behooves us to use it.

Merely examining the list of already published texts, however, one might note that with little effort we would have here the resources for some potentially illuminating linguistic work of a type rarely conducted on American Indian languages. Notice that some of the published texts in Iowa-Oto, Dakota, Omaha-Ponca, and Osage are around 100 years old now, and that there are still at least some speakers left of all of those languages. Here, then, 
is a data base for studies of diachronic syntactic change under the influence of English and bilingualism, if someone would undertake the field work needed to produce comparable modern texts and establish the analytical techniques appropriate for working with such material. It has sometimes been suggested that the results of such analysis might reveal more about the differences in style at dictation speed versus normal speed than about diachronic change, since the older texts were necessarily recorded only as fast as the writer could write. However, such caveats should not be excuses for failing to undertake the task of comparison in the first place.

Perhaps a preliminary, or at least a useful, adjunct to such work would be grammars of the extant older text collections on the model of Elnaudi's Biloxi gramar, which was of necessity written from texts alone. Some of this would be a waste of time, however, without first going over the texts with present-day speakers to verify the transcriptions. Rankin is particularly hesitant about recommending that the Dorsey materials be used uncritically, for Dorsey generally failed to write aspiration, and his upside down letters for $\mathrm{D}, \underline{t}$ and $\underline{k}$ mean different things in different languages (Rankin 1974). There are four series of stops (glottalized, aspirated, volceless tense, and either rolced or voiceless $1 \mathrm{ax}$ ) in all Dhegiha Languages, even though Dorsey recorded all four only in Omaha-Ponca, and Wolff and Matthers in their historical phonologies normalized all the dialects to two or three (grlottolized, volceless and (sometimes) rolced). 
Turning next to the dictionaries, we discover a very mixed group of publications. Although we have titles for nearly every living, language, the quality and reliability of the dictionaries is highly variable. I have neither seen nor received testimony about Marino's Winnebago, but from among the others, the only one I can recommend whout reservation in Hollow's Mandan, and it is difficult to obtain a copy of that. Riggs and Williamson on Santee do not distinguish aspirated and unaspirated stops; Buechel's Lakota has a similar shortcoming. Lowie's Crow is good as far as it goes, but it is essentially a glossary to his texts, and contains all the orthokraphic inconsistencies of a lifetime of mindchanges about phonology. Laflesche falls to write several phonemic distinctions in Osage, according to Rankin, and Washington Matthew's transcription of Hidatsa is also somewhat unreliable, according to Parks and Wicker. Roblnson's Iowa-Oto is merely too short; and all the works can be faulted for entering, too little grammatical information about each item.

I can report on three profects underway to correct for some of this: Rosaria Wicker, a Hidatsa speaker, is revising, the Matthews work at Mary College, and Warren Harbeck is working with several speaicers of Stoney to produce a thorough dictionary of that Nakota dialect. At the University of Colorado, Allan Taylor and I are working on an improved Lakota dictionary, though we have no hope of completing that project in the near future.

Among the criteria for a good dictionary are not merely that it list words accurately transcribed and deflned, but that it 
also provide enough information about the words so that their full paradigms can be constructed. Thus any irregularities in confugation or declension need to be noted, and in Siouan particularly, information about reduplication and ablaut must be provided with each entry. Additional information peculiar to Individual grammars is also required, such as the dative and benefactive forms of Dakota verbs.

In terms of tools for work such as this, I would like to plea for utilization of one which modern technology has provided and which all universities have plenty of, namely, computers. The tedious part of dictionary preparation is sorting and copying, both of which tasks computers do flawlessly, quickly, and without boredom. At Colorado, we are developing a package of programs which will allow an entry to be made fust once, anywhere in the list, and which will ultimately produce typewritten coples of that entry, correctly alphabetized, in as many places in the finished product as we wish, so that perfectly reversed bilingual versions of the work are prepared from a single input form. Those of you who know how computers work realize that the actual process is not nearly as simple as I make it sound, but the point is that most of the tedium is hereby removed from the profect. We will be happy to discuss the details of these programs with anyone who is interested.

The conclusion from this discussion is that wa need more dictionary work of the kinds that are currently in progress. In addition to dictionaries, we need modern (1.e. syntact1- 
94

cally or semantically oriented) grammars of everythinf except Hidatsa, although we do have several excellent and useable grammars or sketches in older styles for all but the Dhegitha and Nakota dialects.

Having said that there is a need for further work in practically everything, let me nevertheless attempt a ranking, of priorities for further synchronic studies. My criteria here are, first, the quality and availability of published information, so that the highest priority goes to basic data gathering and organizing, and second, the existence of speakers able to supply information, so that highest priority goes to the languages in the greatest danger of immediate extinction. (When we come to the discussion of Table Three, these criteria will change.)

Under these criteria, the most pressing need seems to be for grammars of Catawba (if possible), Iowa-Oto, and of all the Dhegiha dialects, in the order Quapaw, Kansa, Osage, OmahaPonca. Of these, the Catawba and the Quapaw may now have to be done like the Biloxi, exclusively on the basis of extant texts. If so, those two would receive lower priority, and gathering data from living speakers of other languages would rank higher. Next, we need as much as we can get on Mandan, texts and dictionaries for Dhegiha and Chiwere, and gramatical information, texts, and dictionaries for Nakota, with emphasis on the dialect variations (Carter). Next, an item I would not have thought of by myself: $G$. Hubert Matthews suggests additional 
advanced syntactic work on Hidatsa as being of high importance, building on and adjusting the hypotheses expounded in his 1965 grammar. Finally, a more thorough grammar of Winnebago, and new or expanded or revised dictionaries, as discussed above, would seem to be in order.

As important as more or less taxonomic descriptive work of this sort is, I feel a strong need to add that Amerindianists should also be providing tempering sorts of input to the currently fashionable but frequently wild speculation about universal language processes, such as descriptions of presupposition, language acquisition processes, what is easy and what is difficult for people about languages, and how language rules work. There is room here for the purely linguistic studies focusing on single topics inspired by generative theories of grammar, such as those conducted by Jack Chambers and his students, Valerie Drummond and Pat Shaw, at Toronto, by Dick Carter at Manitoba, By Earnest Bellam at Calgary, by Tim Dunnigan and his colleagues at Minnesota, and by nyself - all of which concern one or another of the Dakota dialects. We really do know enough about many of the other languages to conduct such work accurately and profitably. Similarly, there is a need in the languages with larger numbers of speakers for all kinds of psycholingusitic and sociolinguistic work, from dialect surveys to bilingualism studies, including studies of when and where each language is used, how styles are differentiated, and how much 1 ripuage 
mixing, is permitted, and of what kinds, and both statistical and longitudinal studies of how these languages are acquired by children. (Bea Medicine feels that this kind of work is most important to the natives themselves.) Such work is entirely feasible among the speakers of Lakota, Stoney, Winnebago, Crow, and Hidatsa, and should form part of the input data for public schools considering billngual programs and for other kinds of language planning for the communities, as well as providing linguists and psychologists with additional information about language behavior. A first step in this direction is a study of language use among the Lakota-speaking Rosebud Sioux, conducted by Elizabeth Grobsmith (Grobsmith In Progress). Much of this work can best be carried on by training speakers of the languages to be studied, rather than teaching the languages to academic types, which brings us to the discussion of Table Three.

\section{Table 3}

\section{Action Linguistics}

(Pedagogical materials and language courses and/or projects producing, such)

Iowa-Oto - Primer and spelling book - Hamilton and Irvin 1843, 1849.

Winnebago - Wisconsin Native American Languages Project - U.W. Milwaukee (second language materials and teacher training).

Stoney - Stoney Cultural Education Programme (Box 29, Morley Alberta) (tapes and transcriptions of history and legends serving as the basis for cultural education in Stoney and for a lexicon. Some work on Stoney as a second language [Harbeck].) 
Santee -

Teton -

Omaha-Ponce -

Osage -

Mandan -

Hidatsa -
Stevens 1836 (Spelling book); Piggs (Misc. lesson books); University of Minnesota American Indian Studies Program (second language naterials); Sisseton-Wahpeton Indian Studies, Bisseton S. Dakota (elementary school workbooks for colors, numbers, common phrases, etc.).

(1) Indian Life Peaders, Sioux Series (a set of about 6 children's books in Sioux - apparently written in English and then transiated, therefore not traditional material) (U.S. Office of Indin Affairs, education division, 1943; now evailable from Haskell Institute, Lawrence, (ansas).

(2) Lakota Woonspe Wowapi. A book of elementary or high school lessons produced by St. Francis Mission at Rosebud, South Dakota and Sinte Gleska College, Rosebud, South Dakota. An emergency production, now being revised. (3) University of Colorado Lakhóta Project (Dept. of Linguistics, University of Colorado, Boulder). Second language materials in 25 lessons for high school and college students; elementary bilingual dictionary for language learners; graded reader. All materials to be available for 1977 . Revisions suitable for younger students and for North Dakota dialects in preparation by Mary College Indian Languages Program, Bismarck, North Dakota). (4) Numerous personal language ressons produced by local teachers in almost all reservation schools.

MeKenney 1850; Dorsey 1873 (Spelling books snd primers).

Montgomery and Requa 1934.

Work in progress at Mary College, Bismarck. Goal: elementary and high school aud:o-lingual course outline for teachers. Directed by Robert Hollow.

Crow Bilingual Education Project, Crow Agency and Hardin, Montana. Second Ianguage teaching materials for elementary and high school, plias materials for teaching arithmetic, Crow culture, and Crow structure using Crow. Also involved in testing, bilingualism research, and Crow language acquisition research. See Matthews 1976 for a more complete report.

Work in progress at Mary College, Bismarck. Goals as for Mandan. 
I have labeled this Table "Action Iinguistics" following a. suggestion by Ken Miner, who in turn credits Sox Tax's term "Action Anthropology" as his inspiration. This to me is the most important single area of current work in Siouan languages, and probably in other American languages as well. Because I feel strongly about the need for this kind of linguistic study, I am very happy to be able to report that there is so much going on at present, and that I probably am not aware of everything. I have listed in Table Three both names of published matierals and names of ongoing bilingual or teaching-materials projects. The only relatively viable modern language for which apparently nothing systematic is in progress along these lines is OmahaPonca (Olson), and even one moribund language, Mandan, is being approached from this direction. Moreover, I have not attempted to recopnize every language class being offered, but rather have tried to include only formal materials preparation projects based on a good understanding of the principles of second language teaching.

The need for continuing this kind of linguistic work seems to me to be obvious, but some explanation may be in order anyway. First, this kind of work has the effect of changing for the better the community's own image of its language. When the language becomes a legitimate subject of study in school or college, stipmata which have been part of its usage for the last few generations disappear. A positive identification of the people with their language is one good way of ensuring that there w11l 
be future generations of speakers.

Secondly, in these days of minority selfossertion, it is clear to the wisest leaders of the communties I an faniliar with that language will be the last uniqueiy Indian possession of the native culture. Everything else, from religion to diet, from handcrafts to ceremonies, is sublect to influence from Whites or other Indians, but a language remains relatively independent of such influences longer than anything, else. Consequently, preservation of the language through writing, and teaching it is one sure way of maintaining ethnic identity a while longer.

A third reason for practicing action linguistics is in the nature of debt-payment. Bob Rankin has pointed out that even in the cases of the nearly dead Dhegiha lanpuapes, there is much old ethnographic material in the languages preserved in archives and text collections, of which most of the Indians are themselves unaware. There is consequently "action lingustics" to be practiced even where the languages are no longex avatiable to the people whose ancestors spoke them, and I thluk there is a duty on our part to practice our arnft thus.

Finally, and perhaps most crucially, it is probably only through action linguistics that we will discover and ba nble to train those younger Indlans who have the interest nnd nbility to become linguists themselves, and it is axionatic in Iinouistics these days that many types of lanouage researoh are best done by trained native speakers. 
I would therefore conclude that another area of need in Siouan studies is the continuation or expansion of projects such as those listed in Table Three. This means that linguists must learn something about language pedagogy, which entalls considerably more than merely "applying linguistics", and that they must also learn enough soclology and ethnology to be able to work with native people on their terms and supplyinf their perceived needs. Both of these activities can be very frustrating to the scholar interested in the nature of deletion in complement constructions, but both are essential if we are to continue to progress in our field. I think it is hard to stress too much, however, that linguists are not naturally equipped for this kind of work, that language teaching is not something inguists necessarily do instinctively or properly, and that anyone who accepts the position of "Linguist" on a project of a pedagogical nature should be prepared either to teach himself some new 1 deas or to work as one member, even a subordinate member, of a team. In these remarks, I am expressing my ow: opinion as reinforced by comments from Ken Miner, Warren Harbeck, and Bea Medicine.

In terms of priorities for this kind of work, I think that here we should encourage it first among the languages with the largest numbers of speakers of the widest variety of ages. In such communities, mistakes can be less harmful, and at the same time, there are presumably greater numbers of resources - more schools, more teachers, etc. The second 
kind of priority should go to the interpratetin of historiogl material for the communities as mentioned.

\section{Table 4}

\section{Other Linguistic Studies}

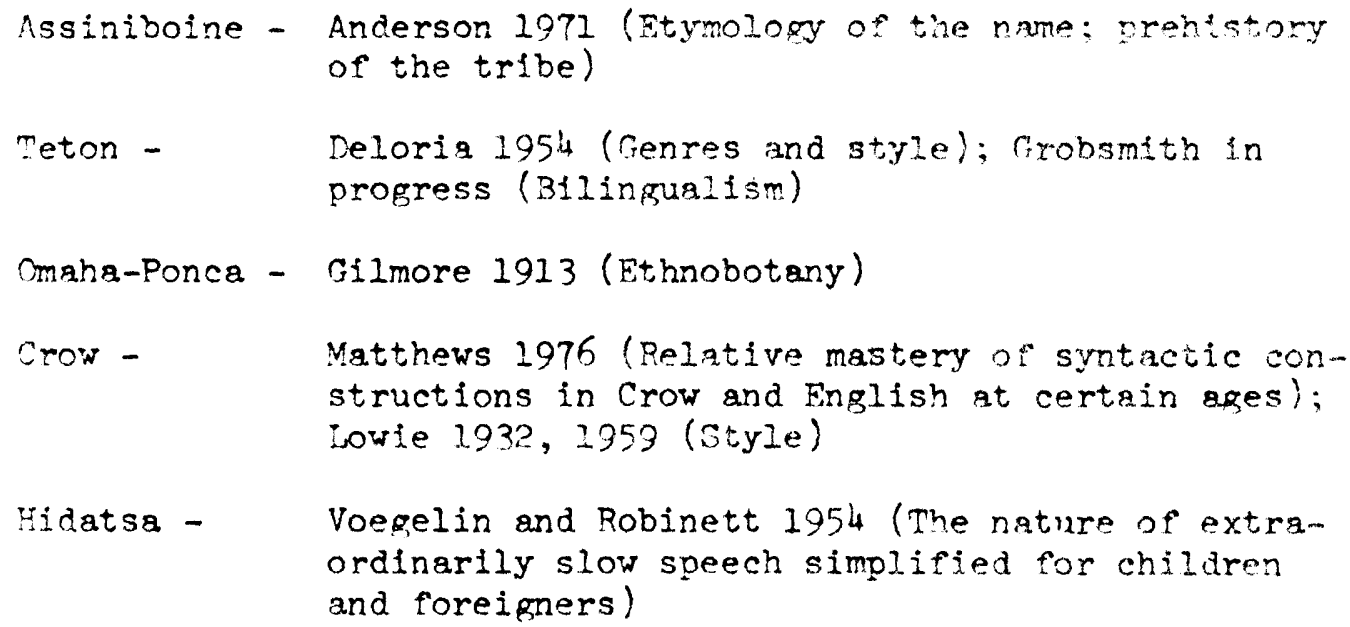

mable 5

Archival Material

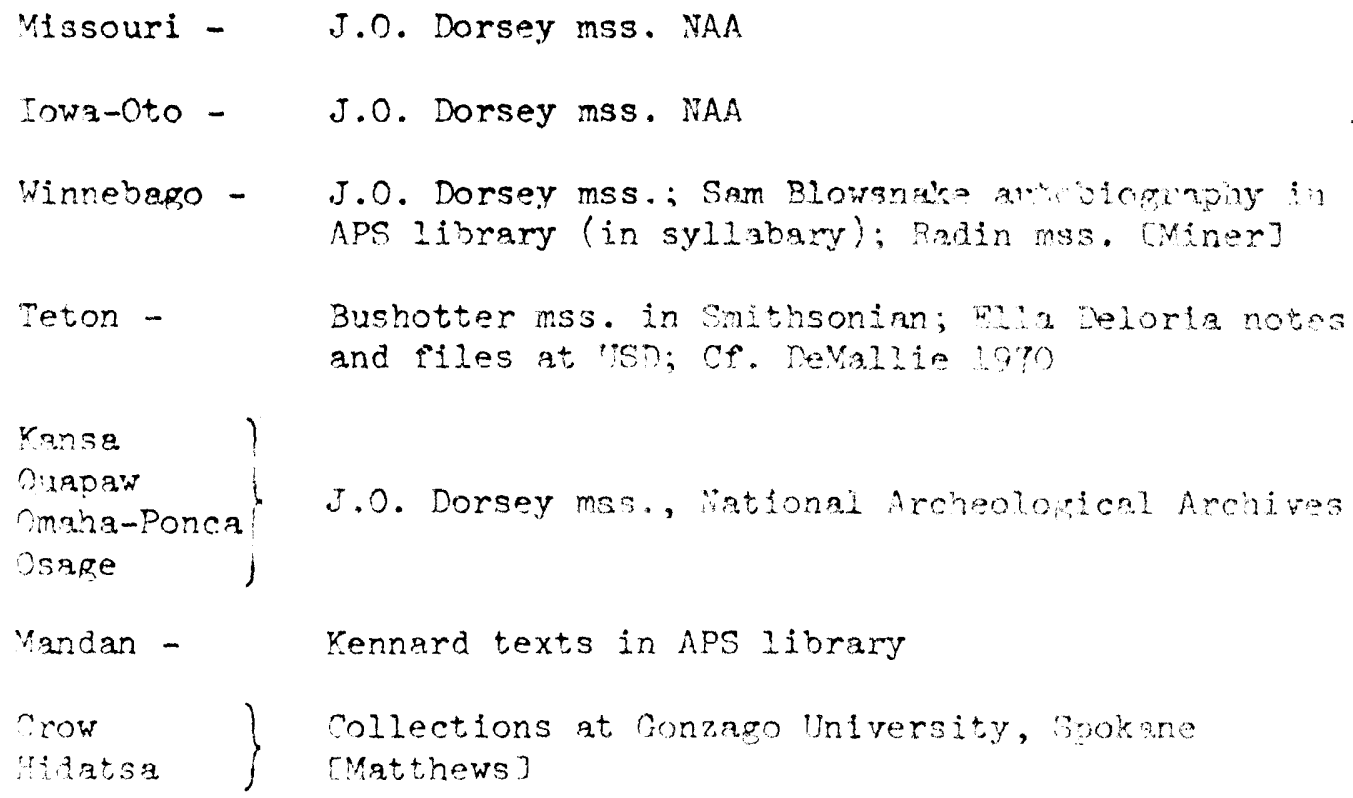


Tables Four and Five are included for the sake of completeness, but there is not much to them. Table Four includes studies of style, ethnoscience, literary genres, and such socioInguistic studies as I am aware of, all of which we could use more of. Table Five lists those manuscript and (archival) file collections of which I am aware and which could be used (cautiously) for more of the kinds of studies I mentioned above, contrasting the languages of 100 years ago with those of today. In this connection, I should mention a suggestion by Bill Powers that a central depository for Siouan research be established. He is presently working toward a reservation-based Research Center in Pine Ridge, South Dakota.

\section{Table 6}

\section{0th century work on subgroupine}

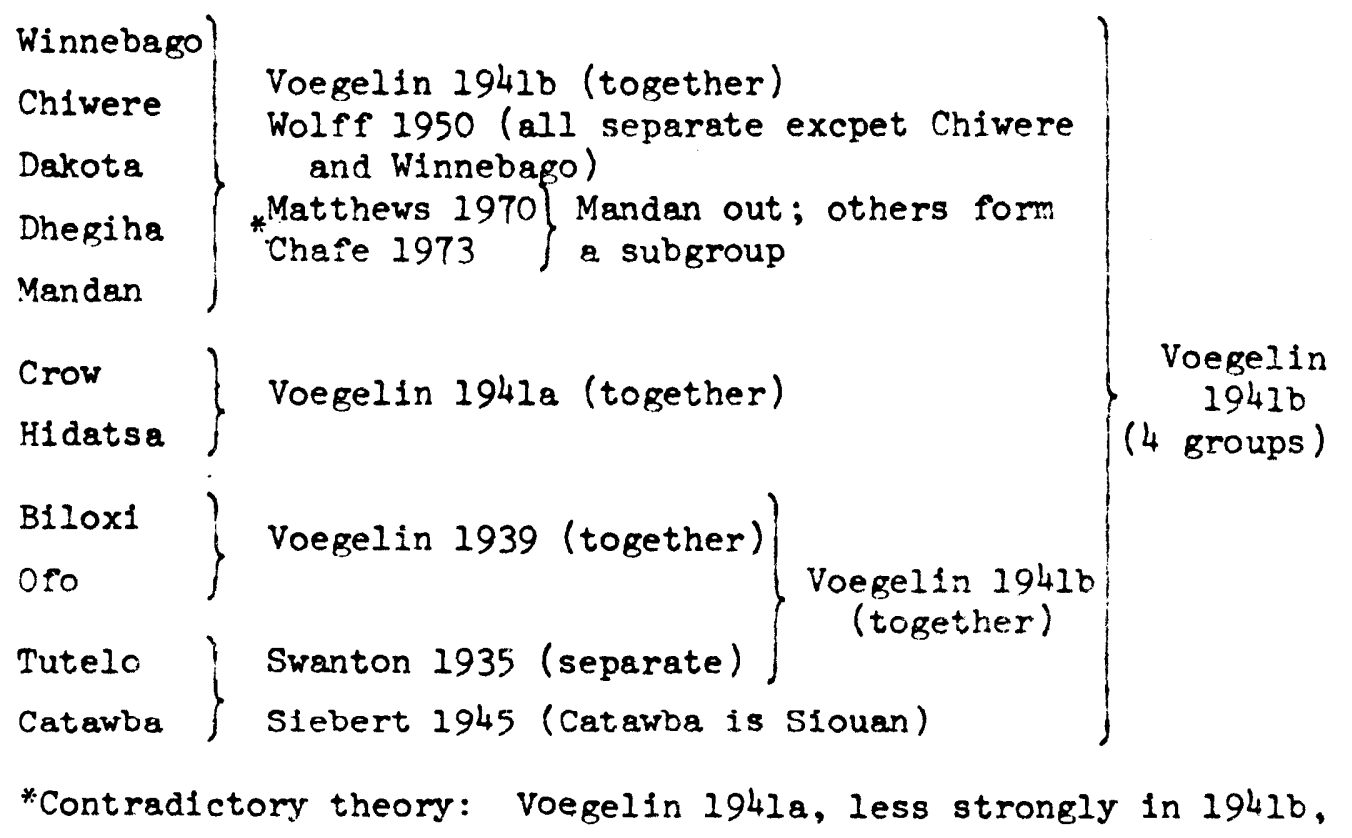


suggests Mandan and Winnebago as a group within a larger group also containing Chiwere, Dakota, and Dhegiha. Here "together" means that the article concluded that the languages do form a coherent subgroup. "Separate" means a conclusion that the languages were separate.

$\ldots-\ldots-\ldots-\cdots-\ldots-\ldots$

Table 7

\section{Comparison and Reconstruction}

Chiwere - Winnebago - Dakota - Dhegiha Comparative Phonology: Dorsey 1885

Omaha-Ponca Development of PSi clusters:

Holmer 1945

Ofo Development of PSi initial clusters involved vowel prothesis and loss of initial member of cluster. Vowel was a-before labials, i- elsewhere:

Holmer 1947

Proto-Siouan Phonology:

Voegelin 1939, 1941a, 194Ib (suggests a few reconstructions and points out several sound correspondences) Wolff 1950-1951 (includes reconstruction of personal affixes)

Chafe 1964 (Proto-S1ougn reconstructions compared with Seneca)

Has 1968, 1969 (Proto-Southeastern Siouan; some Proto.Siouan reconstructions) 
104

\author{
$-P 21-$ \\ Matthews 1970 (reconstructs and describes the develop- \\ ment of continuant consonants) \\ Rankin 1974 (corrects and generally justifies Holmer \\ (1945) after providing accurate Dhegiha data) \\ Proto-Siouan Semantic sub-systems: \\ Matthews 1959b (kinship) \\ Taylor 1976 (motion verbs) \\ At this point, then, it is time to turn to comparative and \\ historical work on Siouan, and here an examination of what has \\ been done will not take us very long. Despite the fact that \\ many of the Siouan languages have been recognized as a group \\ for over 150 years, and despite the fact that serious compara- \\ tive studies date back to 1885 , we know very little more than \\ the broadest outlines of the history of the family or of any \\ language in the family. I have divided diachronic studies of \\ the family into two tables, and here again I have relied \\ heavily on Chafe's Current Trends paper. \\ Table Six lists studies of subgrouping among, the languages, \\ omitting the largely geographically based studies of the 19th \\ century which Chafe discusses. Swanton's 1936 paper demonstrated \\ clear differences between Catawba and Tutelo, thus contradicting \\ earlier assertions of their closeness. As I said at the begin- \\ ning of the paper, Voegelin's classification (1941b) is still \\ taken as the standard, although wolff saw no coherence to the
}


Vississippi Valley group, and Vatthews and Chafe have questioned the inclusion of Mandan in the same group with the other Mississippi Valley languages. It seems to me that there is qery little left to be done here. We may quarrel over details for years to come (after all, scholars are not yet unffied on the issue of subgrouping of the Germanic languages:), but there will probably be no startling new revelations.

A glance at Table Seven, however, shows that the total historical picture is not the same. Table Seven is really just a list of historical studies, and it is a mighty short list. Almost all of what has been done is phonolopical, and even this needs to be reexamined in the light of Rankin's (1974) discovery that four series of stops exist for Dhegiha, and Iras's (1969) admonition not to ignore the recordings of ofo aspiration. Absolutely nothing, has been done in diachronic syntax, and, as Bob Hollow has pointed out, some of the really obvious and probably straightforward problems have not been treated in detail -the instrumental prefix system, for example, (except as examined briefly in Siebert (1945)), or the question of the history of stress placement, which everyone knows is important; but which has been handled only coincidentally. There is need, then, for internal reconstruction in the various languages, and for comparative studies of both morpholopy and syntax. Peal progress on Proto-Siouan presupposes better dat from Dhegiha, however. A more extensive assessment of the work in Tables Six and Seven will be forthcoming, as my contribution to the published pro- 
ceedings of the Oswego conference.

By way of summary and conclusion, then, let me refterate that we need field work on the less well known and dying languages, Mandan, Dhegiha, Iowa-Oto, and Catawba, part1cularly for dictionary work and text collection - both of which are tasks perhaps best undertaken by linguistically trained native speakers - and modern syntactically or semantically based grammars and grammatical studies. Further, we need field work, while it is still possible, to verify and correct texts collected 50 or 100 years ago. In addition, we need sociolinguists and pedagogically oriented linguists for work with the viable languages, and those who prefer to eschew the fieldwork and stay in alr-conditioned libraries will also find plenty to do in the comparative and historical domains. Before I quit, however, I would like to report to you the one thing which everyone who answered my first letter felt obliged to state, even though I had not asked about it specifically. This common plea was for better communication among ourselves. It is to be hoped that some sort of Siouan newsletter will develop soon. 


\section{BIBLIOGRAPHY}

(Note: No entry in the bibliography in Chafe (1973) is duplicated here, though references are made to many of those items, using the same dates.)

Anderson, Russel. 1971. The Assiniboines: some etrnohistorical and ethnolinguistic considerations. University of Texas at Austin M.A. Thesis.

Bellam, Earnest. 1975. Stoney morphology and phonology. University of Calgary Master's Thesis.

Carter, Richard T. 1974. Teton Dakota phonoloky. University of Manitoba Anthropology Papers No. 10.

Chafe, Wallace L. 1973. Siouan, Iroquolan, and Caddoan. Current Trends in Linguistics, ed. Thomas A. Sebeok, 10:11641209.

Chambers, J.K. 1973. A reanalysis of Lakhota relative clauses. University of Toronto: mimeo.

- 1974a. A syntactic argument for NEG transportation in Santee. University of Toronto: mimeo.

- 1975. Notes on Santee relative clauses. University of Toronto: mimeo.

- To appear. Dakota accent. In Linguistic Studies of Native Canada, ed. by F.D. Cook and Jonathan Kaye.

Corduan, Wolfgang. 1974. Subordinating and coordinating particles in Lakhota. University of North Dakota Master's Thesis.

Deloria, Ella. 1929. The Sun Dance of the Oglala Sioux. Jour... nal of American Folklore $42: 354-413$.

DeVallie, Raymond. 1970. A partial bibllography of archival manuscript material relating to the Dakota Indians. In the Modern Sioux, ed. by Ethel Nurge, 312-343. Lincoln: University of Nebraska Press.

Drummond, Valerie. [Dakota relative clauses.] Univarsity of Toronto Master's Thesis.

Dunnigan, Mimothy and Kenneth Truitner. 1975. Boundary markinz and vowel altemation in Dakota. Paper read at the Annual Meeting of the American Anthropolopical Association, San Francisco. 
Einaudi, Paula. 1974. A grammar of Biloxi. University of Coloracio Ph.D. Dissertation. To be published in 1976 by Garlard Publishing Company, New York.

Gordon, Paymona i. 1972. P1tch Accent in Crow. IJAL 38:191200 .

Goshe, F. 1964. Sicux Indian language, grammar, and vocabulary. 153 Harrison Street, Valparaiso, Indiana.

Grant, Paul War Cloud. 1971. Sioux dictionary: over 4,000 words, pronunciation-at-a-glance. Plerre, S. Dakota:

State Publishing Company.

Grobsmith, Elizabeth. In Progress. Bilingualism among the Rosebud Sioux. Ph.D. Dissertation, University of Nebraska.

Holding Eagle, Leroy. 1905. Hymns and Scripture Selections in the Mandan Language. Published for the Fort Berthold Mission, Elbowoods, N. Dakota.

Hollow, Robert C, Jr. 1970a. A Mandan Dictionary. University of California, Berkeley Ph.D. Dissertation. Not available from University microfilms. 298.

- 1970b. A Note on Assiniboine Phonology. ITAL 36:296-

Marshall, Carol. In Progress. [Omaha Phonology]. University of Nebraska M.A. Thesis.

Matthews, G. Hubert. 1976. Bilingual Education at Crow Agency. Studies in Language Learning, to appear.

Powers, William K. In Progress. Collections and editions of songs, myths, and stories from Pine Ridge.

Rankin, Robert L. 1974. Observations on Dhegtha (Siouan) phonetics and phonology. Paper read at the Annual Meeting of the American Anthropological Association, Mexico City.

Robinson, Lila Wistrand. 1972. An Iowa/Otoe-English Dictionary. Manhattan, Kansas: mimeographed.

Rood, David S. 1973. Aspects of subordination in Lakhota and Wichita. In You take the high node and I'll take the low node, ed. Claudia Corum, et al. Chicago: Chicago Linguistic Society.

Scott, Michael Robert. 1975. Informal bibliography of work on Siouan lanquages. Typescript. 


$$
-235-
$$

- 1976. Syntactic combinations of verbs lo iakota sioux

(Feton Dakota). University of North Da'ota Master"s mhesis.

Shaw, Patricia. In Progress. [Dakota Phonology. University of Toronto Ph.D. Dissertation.

- In Press. On restricting the power of global rulss in phonology: A case from Dakota. In Linguistia Stricturas of Vative Canada, ed. by E.D. Cook and Jonatian Kaye.

Smeall, Christopher. 1972a. The Lakota verb. Uiversity ot North Dakota SIL Working Papers.

- 1972b. Topies in Lakota phonolory. University of Michigan B.A. (Honors) Thesis.

Steyaert, Marcia. 1976. Verb reduplication in Dokota. Minnesota Working Papers in Linguistics and the Fhilosophy of Language 3 (Spring 1976): 127-43.

Trylor, Allan R. 1974. Some traits of the Dakota language revisited: Lakhota clause firal enciltics. Paper read at the Annual Meeting of the American Anthropological Associntion, Mexico City.

- 1975. The Colorado system for writing the Lakhota language. The American Indian Culture and Research Joumal (1) $3: 3-12$.

- 1976. On verbs of motion in Siouan languages. IJAL (Cctober issue). 